\title{
Co-parasitism of intestinal protozoa and Schistosoma japonicum in a rural community in the Philippines
}

\author{
Kosala Gayan Weerakoon ${ }^{1,2,3^{*}}$, Catherine A. Gordon ${ }^{1}$, Gail M. Williams ${ }^{2}$, Pengfei Cai ${ }^{1}$, Geoffrey N. Gobert ${ }^{1,4}$,
} Remigio M. Olveda ${ }^{5}$, Allen G. Ross ${ }^{6}$, David U. Olveda ${ }^{6}$ and Donald P. McManus ${ }^{1 *}$

\begin{abstract}
Background: Co-parasitism is a frequent occurrence in impoverished communities in the tropics resulting in a considerable disease burden. While there are extensive reports of intestinal helminthiases, including schistosomiasis japonica, the occurrence and extent of diseases caused by intestinal protozoa (IP) have yet to be investigated in depth in the Philippines. We present a detailed analysis of polyparasitism in a rural community of Northern Samar, focusing on co-infections of IP with Schistosoma japonicum.
\end{abstract}

Methods: A descriptive cross sectional study was carried out in 2015 across 18 barangays (villages) endemic for S. japonicum in Northern Samar, the Philippines to assess the burden of human schistosomiasis and IP infections. Faecal samples collected from 412 participants from the 18 barangays were included in the final molecular analysis. A multiplex quantitative PCR assay was developed and used for the detection of Blastocystis spp., Entamoeba histolytica, Cryptosporidium spp. and Giardia duodenalis in stool samples. The findings were combined with previous results of droplet digital PCR diagnosis of individuals from the same 18 barangays infected with S. japonicum determined using the same stool samples for analysis.

Results: Mean age of the study participants was 40.3 years (95\% Cl: 38.8-41.8) with 53\% ( $n=218)$ being males. Prevalence of S. japonicum (74.5\%) and Blastocystis spp. (58.7\%) was significantly higher compared to other infections, with E. histolytica having the lowest prevalence (12.1\%). A majority of individuals were infected with more than one parasite with two infections being most common $(n=175,42.5 \%)$. The prevalence of individuals with two parasites was significantly higher than all others with $27.9 \%(n=115)$ subjects harbouring a single parasite species. Of individuals with two infections, S. japonicum and Blastocystis spp. were the most common combination ( $n=110,62.9 \%)$. Examining age within the population, 58.5\% $(n=38)$ of school-aged children and $60.1 \%(n=14)$ of women of child bearing age harboured at least two parasite species.

Conclusions: The study revealed that polyparasitism with IP infections and schistosomiasis japonica is highly prevalent in individuals in Northern Samar which likely contributes to the significant public health and socio-economic burden suffered by this population. More generally, the findings are of relevance when considering implementation of integrated control strategies for intestinal parasites.

Keywords: Polyparasitism, Intestinal protozoa, Schistosomiasis japonica, The Philippines

\footnotetext{
* Correspondence: kosala.weerakoon@gimrberghofer.edu.au; Don.McManus@qimrberghofer.edu.au

${ }^{1}$ Molecular Parasitology Laboratory, Infectious Diseases Division, QIMR

Berghofer Medical Research Institute, Brisbane 4006, Australia

Full list of author information is available at the end of the article
}

(c) The Author(s). 2018 Open Access This article is distributed under the terms of the Creative Commons Attribution 4.0 International License (http://creativecommons.org/licenses/by/4.0/), which permits unrestricted use, distribution, and reproduction in any medium, provided you give appropriate credit to the original author(s) and the source, provide a link to the Creative Commons license, and indicate if changes were made. The Creative Commons Public Domain Dedication waiver (http://creativecommons.org/publicdomain/zero/1.0/) applies to the data made available in this article, unless otherwise stated. 


\section{Multilingual abstracts}

Please see Additional file 1 for translations of the abstract into the five official working languages of the United Nations.

\section{Background}

Concomitant intestinal parasitic worm infections, with water-borne intestinal protozoa (IP), occur frequently in impoverished communities and cause a serious public health burden with significant socio-economic impact $[1,2]$. Many species of parasitic protozoa and intestinal helminths occur primarily in tropical zones due to the requisite shared environmental requirements of moist warm soil and water $[1,3,4]$. Aetiological factors that lead to infection with most intestinal parasites include poor socio-economic, sanitary and hygienic conditions and, with the schistosome blood flukes, the absolute requirement for suitable freshwater snail habitats and frequent human water contact $[1,3]$. The high prevalence of these parasites and their considerable overlap in geographic distribution means that the potential for coinfection is high and likely to be more common than single infections in endemic areas [4-7]. Polyparasitism is thus widespread in endemic regions in the tropics, and the health impacts of co-infection can be more severe than when an individual is infected with a single parasite species $[1,5,8]$.

It is estimated that schistosomiasis results in more than 40000 deaths every year and some 700 million are at risk of infection in endemic areas [9, 10], whereas other intestinal helminths, for example the soil transmitted helminths (STH) (including Trichuris trichiura, Ascaris lumbricoides and the hookworms Ancylostoma duodenale and Necator americanus), infect more than one billion people worldwide [11]. Waterborne IPs cause substantial global morbidity and mortality with the most common and important species including Entamoeba histolytica, Giardia duodenalis, Cryptosporidium spp. and Blastocystis spp. Amoebiasis, caused by E. histolytica, one of the most deadly of the protozoa, alone accounts for 100000 annual deaths around the world. Giardiasis is globally distributed and has a prevalence of around $30 \%$ in the developing world with a significant disease burden in poverty-related communities [12-14].

Pathogenic intestinal parasitic infections lead to significant nutritional deficiencies with gastrointestinal morbidity and mortality, particularly among immune-compromised individuals, pregnant women and children in developing countries $[12,15,16]$. Amoebiasis leads to diarrhoea, amoebic dysentery, colitis and hepatic abscess [12, 17]. Generally, G. duodenalis infection is self-limiting but it can also result in chronic disease with persistent diarrhoea leading to malabsorption and weight loss $[18,19]$. Cryptosporidium also results in a self-limiting, asymptomatic infection but can lead to severe diarrhoea, particularly in immunocompromised people and in children [20-22]. Blastocystis spp. is a common anaerobic IP of humans but its pathogenicity is still under debate $[23,24]$.

While polyparasitism is highly prevalent in many endemic areas, limited large scale studies have been conducted in terms of assessing its true burden and impact on health in these regions $[7,25]$. This could possibly be due to the lack of screening procedures with good diagnostic performance that allows simultaneous examination of an individual for the presence of IPs and helminths. As such, most studies have focussed on the identification of single rather than multiple parasites in infected individuals [26]. Moreover, the interpretation of the clinical picture becomes complicated as presenting manifestations often tend to be quite generalised and similar between intestinal parasites [2527]. Whereas immunodiagnostic methods can lack specificity and microscopy-based techniques lack sensitivity and are reliant on the capability of the microscopist, modern DNA-based molecular diagnostic tools, such as quantitative polymerase chain reaction (qPCR) and droplet digital PCR (ddPCR), can be applied for highly sensitive concurrent detection of these parasitic infections $[5,28,29]$. The multiplex qPCR approach, in particular, is helpful in simultaneous screening of multiple parasites in a single clinical specimen and has the additional advantages of minimizing reagent costs and processing time [5, 30, 31].

S. japonicum, is highly endemic in the Philippines $[5,6$, 32-34] and there are also reports of variable prevalence of IPs in both urban and rural communities [35-38], but there have been no in depth investigations of the occurrence and extent of waterborne, poverty-related protozoan infections. Here we present a detailed analysis, of IP infections in a rural community of Northern Samar province, the Philippines, with a particular focus on co-infections with S. japonicum.

\section{Methods \\ Sample collection, processing and storage}

This descriptive cross-sectional study was carried out across eighteen barangays (villages) endemic for schistosomiasis japonica in Northern Samar (Palapag and Laoang municipalities), the Philippines (Fig. 1), to assess the burden of human schistosomiasis and IP infections. The study cohort has been described previously and the majority of the population in the area live below the poverty line and are faced with poor sanitation, lack of good hygiene practices, and limited water supply [32, 39]. The study area is known to be endemic for multiple parasitic diseases but the status of intestinal protozoan infections has not been systematically determined [5, 32, 39]. 


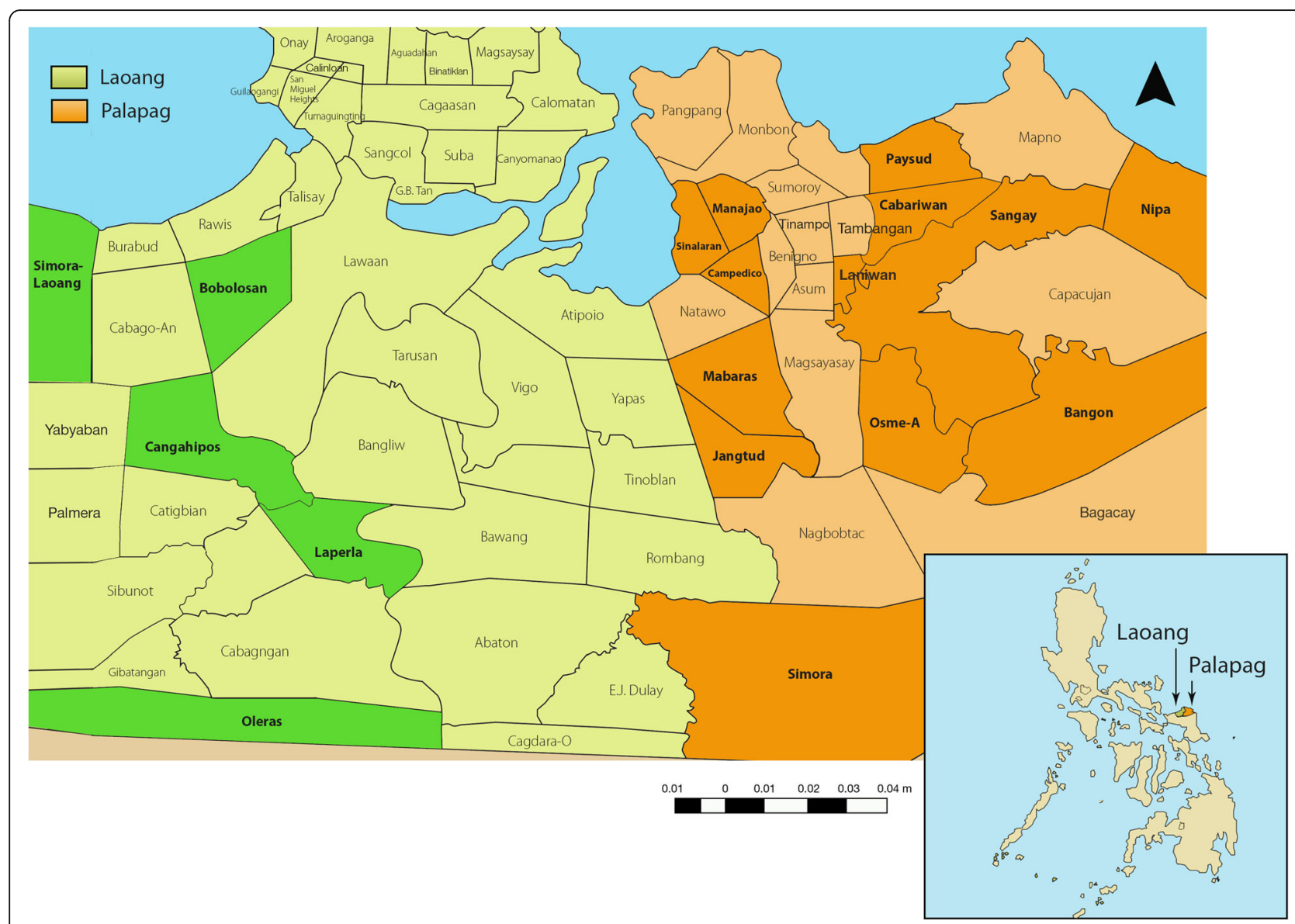

Fig. 1 Map of the Philippines showing the Palapag and Laoang municipalities with the 18 study barangays. (Adapted from reference [40])

IP infection status (Blastocystis spp., Entamoeba histolytica, Cryptosporidium spp. and Giardia duodenalis) was assessed by a multiplex qPCR assay using DNA isolated from stool samples. Previous results of ddPCR diagnosis of $S$. japonicum infections using the same stool samples [40], were used for the analysis and comparison of infection status of $S$. japonicum with the IPs.

Stool samples were collected over a period of one week in August 2015. This study was conducted since 2012 as part of a large survey to evaluate the hepatic morbidity associated with schistosomiasis [32]. All participants who were followed up as a part of this hepatic morbidity investigation were considered in this study. Additionally, final inclusion into the current study was based on having a completed consent form and submitting a stool sample for analysis. A total of 452 participants from the 18 barangays were recruited for the study. Faecal samples were collected in a pre-labelled stool cup from each participant and age and gender were obtained at sampling. The Kato-Katz test was performed on faecal samples for the initial detection of $S$. japonicum infection and participants who were positive were treated with praziquantel. Around $10 \mathrm{~g}$ of faeces was fixed in $80 \%$ ethanol and stored at $4{ }^{\circ} \mathrm{C}$ for DNA extraction and PCR analysis carried out later at QIMR Berghofer Medical Research Institute (QIMRB) in Australia.

\section{DNA extraction}

DNA isolation from faecal samples was performed using the Maxwell ${ }^{\circ} 16$ Instrument (Promega Corporation; Wisconsin, USA) incorporating the Maxwell ${ }^{\circ} 16$ LEV Plant DNA kit, as described previously [40]. Based on the adequacy of sample provided and successful DNA extraction, a final total of 412 samples were utilized in the subsequent molecular and data analysis.

\section{qPCR analysis}

A multiplex qPCR was established employing primers and probes published earlier [30, 41] for Blastocystis spp., E. histolytica, Cryptosporidium spp. and G. duodenalis (Table 1). The total volume of $20 \mu \mathrm{l}$ reaction mixture contained, $10 \mu \mathrm{l}$ of GoTaq ${ }^{\circ}$ Probe qPCR master mix (Promega Corporation, Madison, USA), optimised primer and probe concentrations (Table 1), and $2 \mu \mathrm{l}$ of template DNA. Thermocycling conditions were $3 \mathrm{~min}$ at $95^{\circ} \mathrm{C}$ with subsequent 40 cycles at $95^{\circ} \mathrm{C}$ for $30 \mathrm{~s}, 55^{\circ} \mathrm{C}$ for $30 \mathrm{~s}$ and $72{ }^{\circ} \mathrm{C}$ for $30 \mathrm{~s}$ 
Table 1 Details of the multiplex qPCR primers and the probes used in the study

\begin{tabular}{|c|c|c|c|c|c|c|c|}
\hline Parasite & Gene target & $\begin{array}{l}\text { GenBank } \\
\text { Accession \# }\end{array}$ & Reference & Primer / probe & Sequence $\left(5^{\prime} \rightarrow 3^{\prime}\right)$ & $\begin{array}{l}\text { Product } \\
\text { size (bp) }\end{array}$ & $\begin{array}{l}\text { Final } \\
\text { concentration } \\
(\mathrm{nmol} / \mathrm{L})\end{array}$ \\
\hline \multirow[t]{3}{*}{ Blastocystis spp. } & \multirow[t]{3}{*}{ SSU rRNA } & \multirow[t]{3}{*}{ AY244621 } & \multirow[t]{3}{*}{ [41] } & Forward primer & GGTCCGGTGAACACTITGGATTT & \multirow[t]{3}{*}{119} & 350 \\
\hline & & & & Reverse primer & CCTACGGAAACCTTGTTACGACTTCA & & 350 \\
\hline & & & & Probe & FAM-TCGTGTAAATCTTACCATTTAGAGGA-MGBNFQ & & 120 \\
\hline \multirow[t]{3}{*}{ Entamoeba histolytica } & \multirow[t]{3}{*}{ SSU rRNA } & \multirow[t]{3}{*}{ X75434.1 } & \multirow[t]{3}{*}[30,71]{} & Forward primer & AACAGTAATAGTTCTTTGGTTAGTAAAA & \multirow[t]{3}{*}{135} & 200 \\
\hline & & & & Reverse primer & CTTAGAATGTCATTTCTCAATTCAT & & 200 \\
\hline & & & & Probe & ROX-ATTAGTACAAAATGGCCAATTCATTCA-IBRQ & & 80 \\
\hline \multirow[t]{3}{*}{ Giardia duodenalis } & \multirow[t]{3}{*}{ SSU rRNA } & \multirow[t]{3}{*}{ M54878.1 } & \multirow[t]{3}{*}{ [30] } & Forward primer & GACGGCTCAGGACAACGGTT & \multirow[t]{3}{*}{63} & 200 \\
\hline & & & & Reverse primer & TTGCCAGCGGTGTCCG & & 200 \\
\hline & & & & Probe & CY5-CCCGCGGCGGTCCCTGCTAG-IBRQ & & 100 \\
\hline \multirow[t]{3}{*}{ Cryptosporidium spp. } & \multirow[t]{3}{*}{ COWP } & \multirow[t]{3}{*}{ AF248743.1 } & \multirow[t]{3}{*}{ [30] } & Forward primer & CAAATTGATACCGTTTGTCCTTCTG & \multirow[t]{3}{*}{150} & 300 \\
\hline & & & & Reverse primer & GGCATGTCGATTCTAATTCAGCT & & 300 \\
\hline & & & & Probe & HEX-TGCCATACATTGTTGTCCTGACAAATTGAAT-IBFQ & & 75 \\
\hline
\end{tabular}

SSU rRNA Small subunit ribosomal RNA, COWP Cryptosporidium oocyst wall protein

in a Corbett RotorGene 6000 instrument (Qiagen, Hilden, Germany). No template DNA and positive controls were used in all assays. Positive controls included cultured plasmid DNA of Blastocystis spp., E. histolytica, Cryptosporidium spp., and G. duodenalis, which were kindly provided by the Clinical Tropical Medicine Group of QIMRB and the School of Veterinary Science, University of Queensland (Gatton Campus).

A serial 10-fold dilution of DNA extracted from each plasmid control was used to prepare a standard curve. The dilution series was used to optimize the multiplex qPCR assay and to set the cycle threshold $(\mathrm{Ct})$ value cut-offs. Optimization was done as mono-assays of all four of the qPCRs (for Blastocystis spp., E. histolytica, Cryptosporidium spp., and G. duodenalis) and thereafter in the multiplex assay. The maximum $\mathrm{Ct}$ value considered to be positive was set at 35 .

\section{Statistical analysis}

Findings of the multiplex qPCR assay performed here were combined with our previous results of ddPCR diagnosis of S. japonicum infections using the same cohort stool samples [40]. Data analysis was done using Microsoft Excel 2010 (Microsoft; LA, USA), GraphPad Prism 7 (GraphPad Software, Inc.; California, USA) and R 3.4.0 ( $R$ foundation; Vienna, Austria) software. The Venn diagrams were designed using an online tool available at: http://bioinformatics.psb.ugent.be/webtools/Venn/, and then modified. Prevalence for all five parasites (Blastocystis spp., E. histolytica, Cryptosporidium spp., G. duodenalis and S. japonicum) was calculated from the total study sample. Infection intensities across age, gender and municipalities were analysed with Mann Whitney and Kruskal-Wallis tests for statistical significance. The chi-square $\left(\chi^{2}\right)$ test was used to test the associations between prevalence of S. japonicum and the protozoa, and age, gender and municipalities. The odds ratio $(O R)$ was used to assess the strength of association between multiple infections with a 95\% confidence interval (95\% CI). Statistical inferences were made with a significance level of $5 \%(P=0.05)$.

\section{Results}

\section{Description of study population}

Of the total group $(n=412), 218(53 \%)$ were male and the mean age of the entire sample was 40.3 years $(95 \%$ CI: 38.8-41.8). The distribution of prevalence and intensity of the five parasitic infections in the total group, as well as across different municipalities, and age and gender categories are shown in Table 2.

\section{Prevalence of infections}

Prevalence was stratified by gender, age and municipality (Table 2). The prevalence of S. japonicum (74.5, 95\% CI: 70.3-78.7) and Blastocystis spp. (58.7, 95\% CI: 54.063.5) were significantly higher $(P<0.0001)$ compared to other infections (Cryptosporidium spp.; 21.8, 95\% CI: 17.9-25.8, G. duodenalis; 19.2, 95\% CI: 15.4-23.0, E. histolytica; 12.1, 95\% CI: 9.0-15.3). The prevalence of $E$. histolytica was significantly lower than all other infections $\left(\chi^{2}=536.6, P<0.0001\right)$. Prevalence distribution of single and multiple parasite infections across different, age, gender and municipality categories are given in Table 3. There was no significant association of age or gender with different levels of co-infections. The majority of subjects who were infected with $S$. japonicum also had one or more IP co-infection (248/307, 80.8\%) compared with individuals negative for $S$. japonicum (Fig. 
2a), although the difference was not statistically significant $\left(\chi^{2}=2.61, P \geq 0.05\right)$.

The majority of study participants had at least two infections $(n=269,65.3 \%)$ (Table 3). The prevalence of dual infections was significantly higher than all other infections $\left(\chi^{2}=185.2, P<0.0001\right)(n=175,42.5,95 \%$ CI: 37.7-47.2) and the prevalence of single infections $(n=115,27.9,95 \%$ CI: 23.6-32.2) was significantly higher than triple and quadruple infections $\left(\chi^{2}=88.8\right.$, $P<0.0001)$. Of the dual infections, S. japonicum and Blastocystis were the most common combination $(n=110$, $62.9 \%)$. Of the single infections 59 (14.3\%) had schistosomiasis while 38 (9.2\%) had Blastocystis infection (Fig. 3). Only three $(0.73 \%)$ individuals (all female, aged between 34 and 54 years) harboured all five parasites. Of the total $(n=412), 28(6.8 \%)$ were negative for all tested parasites. Of the school-aged children (age less than 18 years; $n=65), 58.5 \%(n=38)$ had two or more infections and only six $(9.2 \%)$ were negative for all tested parasites. Of women of child-bearing age (18-35 years; $n=23), 14(60.1 \%)$ had at least two infections while only three $(13.0 \%)$ had no infections.

\section{Coinfections with S. japonicum}

Blastocystis was the most frequent co-infection occurring with $S$. japonicum ( $n=185,44.9 \%)$; E. histolytica was the least frequent $(n=41,9.9 \%)\left(\chi^{2}=179.7, P<0.0001\right)$. The co-infection prevalence of Cryptosporidium spp. and $G$. duodenalis with S. japonicum were 73 (17.7\%) and 60 (14.6\%), respectively (Fig. 3).

Of the single and multiple co-infection combinations, dual S. japonicum and Blastocystis spp. infection was the most prevalent $(n=110,26.7 \%)$. Those with a frequency of at least 20 were $S$. japonicum alone ( $n=59,14.3 \%$ ), Blastocystis spp. alone $(n=38,9.2 \%)$, S. japonicum and Cryptosporidium spp. dual infection $(n=25,6.1 \%), S$. japonicum, Blastocystis spp. and E. histolytica triple infection ( $n=20,4.9 \%)$ and, S. japonicum, Blastocystis and Cryptosporidium spp. quadruple infection $(n=20,4.9 \%)$ (Fig. 3).

\section{Associations of multiple infections}

Calculated odds ratios showed cryptosporidiosis had a positive association with giardiasis (OR: 2.59, 95\% CI: 1.51-4.42) and a negative association with Blastocystis spp. infection (OR: 0.57, 95\% CI: 0.35-0.91). None of the other infections had significant associations with each other (Fig. 2b).

\section{Intensity of infection}

Infection intensity of S. japonicum was significantly higher in Laoang municipality (copy number index $[\mathrm{CNI}]=93.4$, 95\% CI: 50.0-136.7, $P<0.05$ ), and the intensity of Blastocystis spp. infection was significantly higher in Palapag municipality $(\mathrm{Ct}$ score $=26.6,95 \%$ CI: 25.9-27.3, $P<0.05)$ (Table 2). The infection intensity of Blastocystis spp. varied significantly across different age categories $(P<0.005)$ (Table 2). Infection intensities of $S$. japonicum and Blastocystis spp. were significantly higher among males $(P<0.001)$. There were no significant differences in infection intensity with the other protozoan infections between males and females.

\section{Discussion}

The current study reveals the extensive burden of multiple IP infections in the province of Northern Samar, a historically known endemic area for schistosomiasis $[6,32,34$, 40]. The majority of individuals in the study harboured at least two infections $(n=269,65.3 \%)$ and only $28(6.8 \%)$ had no infection at all. Moreover, the majority of subjects with $S$. japonicum infection were also co-infected with one or more IP (Fig. 2a). The most common individual parasites recorded were S. japonicum $(74.5 \%)$ and Blastocystis spp. (58.7\%). A very high prevalence of schistosomiasis japonica using advanced molecular diagnostics has previously been reported $[5,6,40]$. There is much continuing debate as to whether Blastocystis spp. is pathogenic or commensal in humans. This protozoan has been reported to give rise to gastrointestinal and dermatological manifestations but is common among infected individuals showing no clinical symptoms [23, 35, 42, 43]. Despite the fact that some patients experience symptoms such as diarrhoea, abdominal pain and bloating (which are mostly self-limiting) there are no confirmed virulent or pathogenic mechanisms explained in association with Blastocystis and it is generally termed a non-invasive organism [23, $42,43]$. However, it has also been reported that the elimination of heavy Blastocystis colonization results in symptom resolution. It is also considered that Blastocystis spp. may potentially play a role in the pathogenesis of chronic intestinal conditions such as irritable bowel syndrome [44, 45]. In contrast, the truly pathogenic protozoa Entamoeba, Cryptosporidium and Giardia present reported direct pathogenic effects such as red cell phagocytosis, disruption of gut mucosal epithelial cells and resultant diarrhoea and activation of immune responses [12, 20,46]. The prevalence of Cryptosporidium spp. and G. duodenalis was significantly higher than that of $E$. histolytica in the region surveyed in our study. Individuals co-infected with these IPs have been reported globally with varying frequencies $[47,48]$.

In this study locality, cryptosporidiosis had a significant positive association with giardiasis but a negative association with blastocystosis (Fig. 2b), which contrasts with a study in rural Côte d'Ivoire, which reported a positive association between Blastocystis spp. and G. duodenalis [25]. G. duodenalis is believed to be mostly antagonistic (i.e. hindering infection by another parasite 


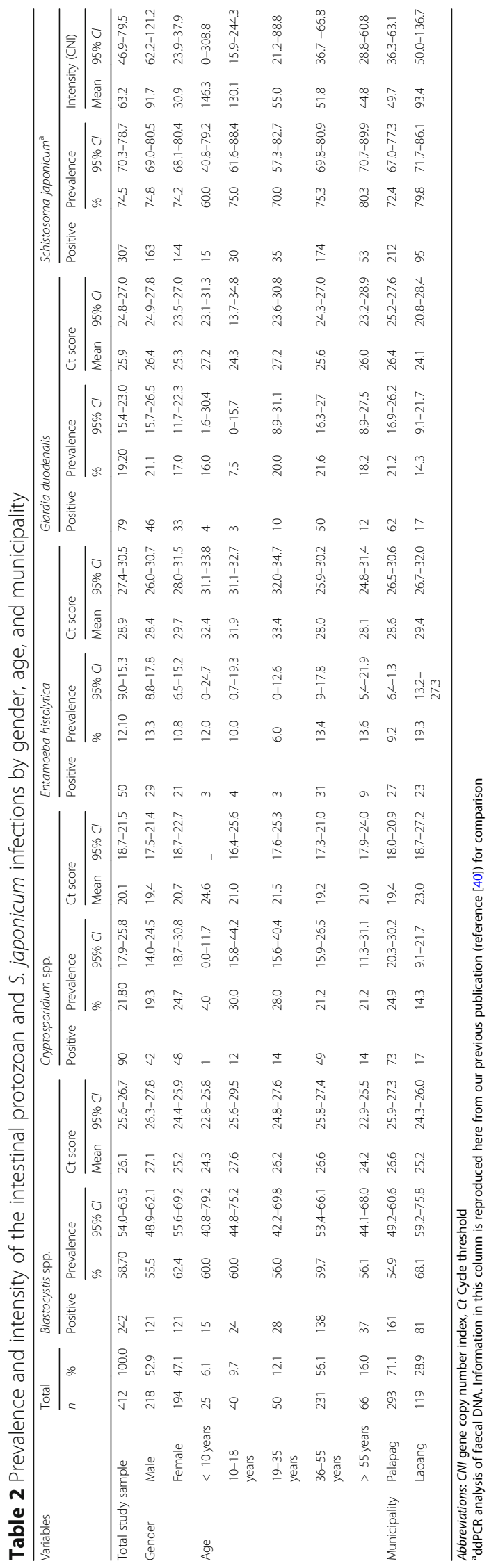


Table 3 Prevalence of multiple co-infections with intestinal protozoa and S. japonicum by gender, age and municipality categories

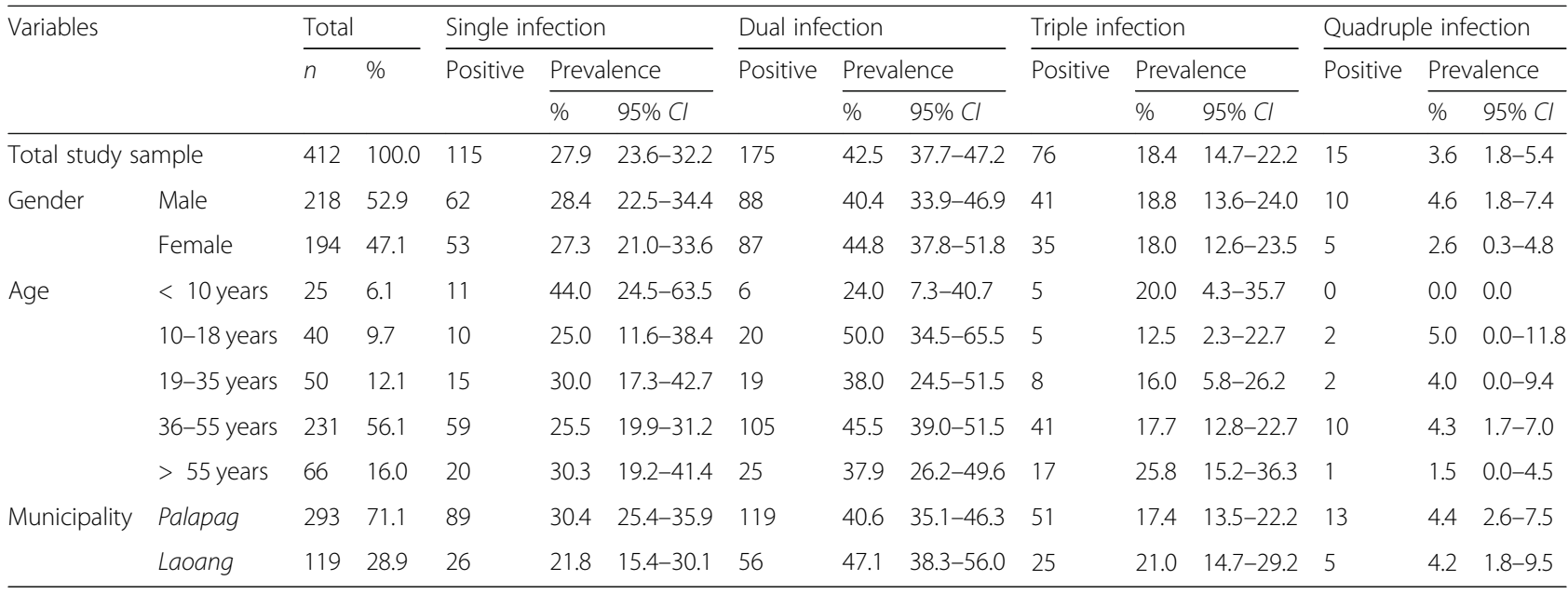

species) for concomitant infections $[49,50]$. This association with Giardia is thought to arise either because of adverse physical interactions with other species or because of an abnormal overgrowth of bacteria in the jejunum [49]. A strong association between G. duodenalis and $S$. mansoni has been previously reported [28] and although no association was found between S. japonicum and G. duodenalis dual infection in the current study, we did record multiple IP co-infections with the schistosome. However, the prevalence of some parasites was low, which can affect the external validity of the strength of associations between different species.

There was no significant difference in the prevalence of any of the parasites in males and females in this study population. However, gender differences in the incidence and severity of parasitic diseases including schistosomiasis, IP and STH infections have been found previously [51]. This could mostly be attributed to gender-related behavioural differences, such as in occupational and household activities and/or to differences in the immune response amongst men and women, due to varying levels of sex hormones [51-53]. Over $60 \%$ of the females of child-bearing age had at least two infections while only $13 \%$ were negative for all tested parasites. This represents a potentially serious public health issue, particularly in relation to possible effects on pregnancy-associated complications such as intrauterine growth restriction and anaemia, leading to poor pregnancy outcomes [54]. Additionally, $>50 \%$ of the school-aged children harboured at least two parasite species and it is recognised that the chronic effects of these infections can have direct negative effects on growth, development and school performance $[47,55,56]$.

The IPs infecting individuals from the study cohort share many aetiological and risk factors in common with schistosomes such as poor socio-economic status, a low level of education, limited access to safe water sources, poor sanitation and imperfect hygiene practices [33, 57, 58]. Hence the key control measures to target these parasites include improvement in access to clean water and sanitation, maintenance of good hygiene (WASH), health

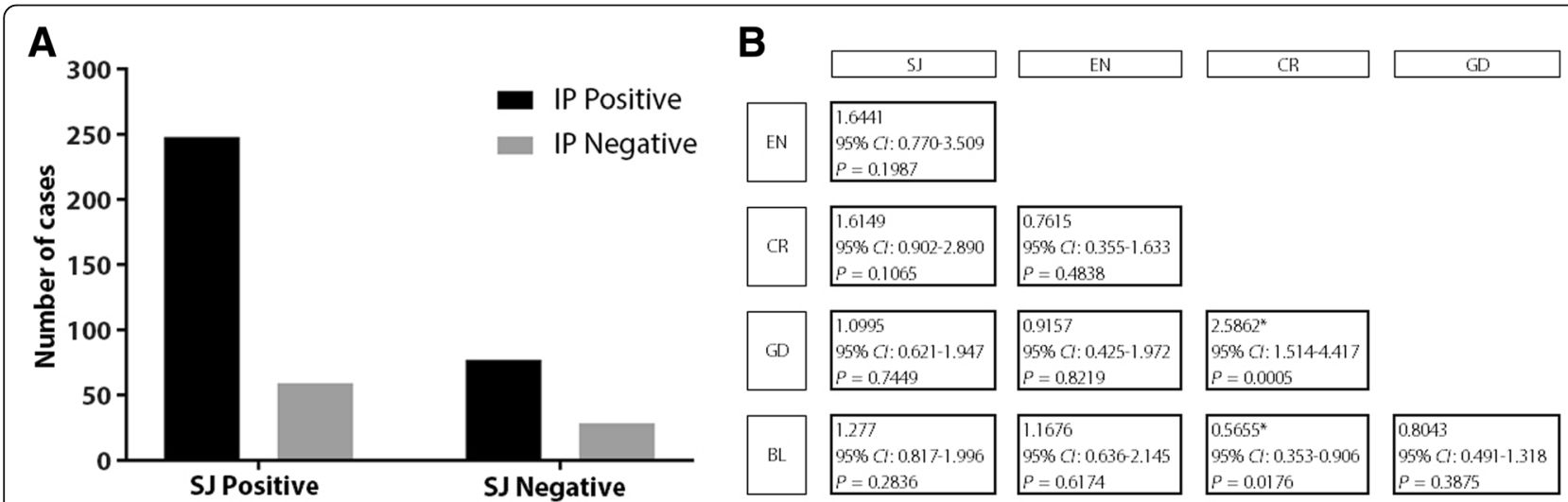

Fig. 2 a Prevalence of IP (at least one co-infection) in subjects positive for S. japonicum infection compared with those S. japonicum-negative; b Odds ratio matrix showing associations between the four protozoans (BL, GD, CR and EN) and SJ infections. BL, Blastocystis spp.; CR, Cryptosporidium parvum; EN, Entamoeba histolytica; GD, Giardia duodenalis; SJ, Schistosoma japonicum. * Statistically significant associations 


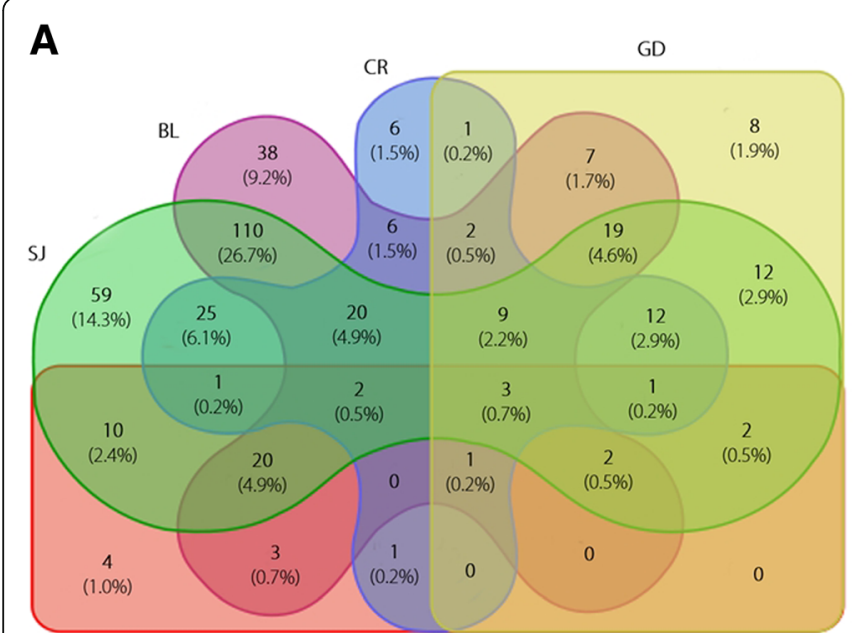

EN

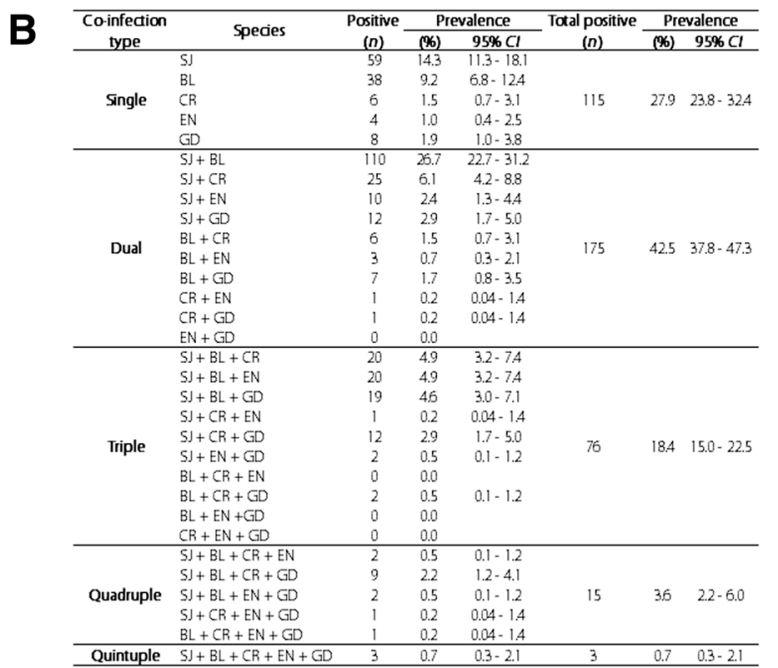

Quintuple $\mathrm{SI}+\mathrm{BL}+\mathrm{CR}+\mathrm{EN}+\mathrm{CD}$

Fig. 3 a Venn diagram showing the prevalence of single and multiple co-infections. b Prevalence of individual and multiple co-infection combinations. BL, Blastocystis spp.; CR, Cryptosporidium parvum; EN, Entamoeba histolytica; GD, Giardia duodenalis; SJ, Schistosoma japonicum

education, and mass drug administration (MDA) in endemic regions [33, 57-59]. The Laoang and Palapag municipalities are compromised in these respects in that villagers there mostly consume water from shallow wells, rivers and springs, which are exposed to water runoff and can easily be contaminated with sources such as waste water from leaking/poorly maintained septic systems (authors' observations; Fig. 4), making it highly conducive to infection transmission and the likelihood of frequent co-infections [5,33].
Schistosomiasis can result changes to local and systemic human host immunity, such as immune dysregulation with suppression of inflammatory Th1/17 responses. Moreover, schistosome-induced damage to the intestinal mucosa following egg entrapment and granuloma formation can pre-dispose the host to different IP infections and facilitate chronic protozoan infections [8, 28, 60-62]. Concomitant multiple parasite infections generally carry a higher morbidity compared with single infections. Multiple intestinal parasitic infections can cause additive or multiplicative
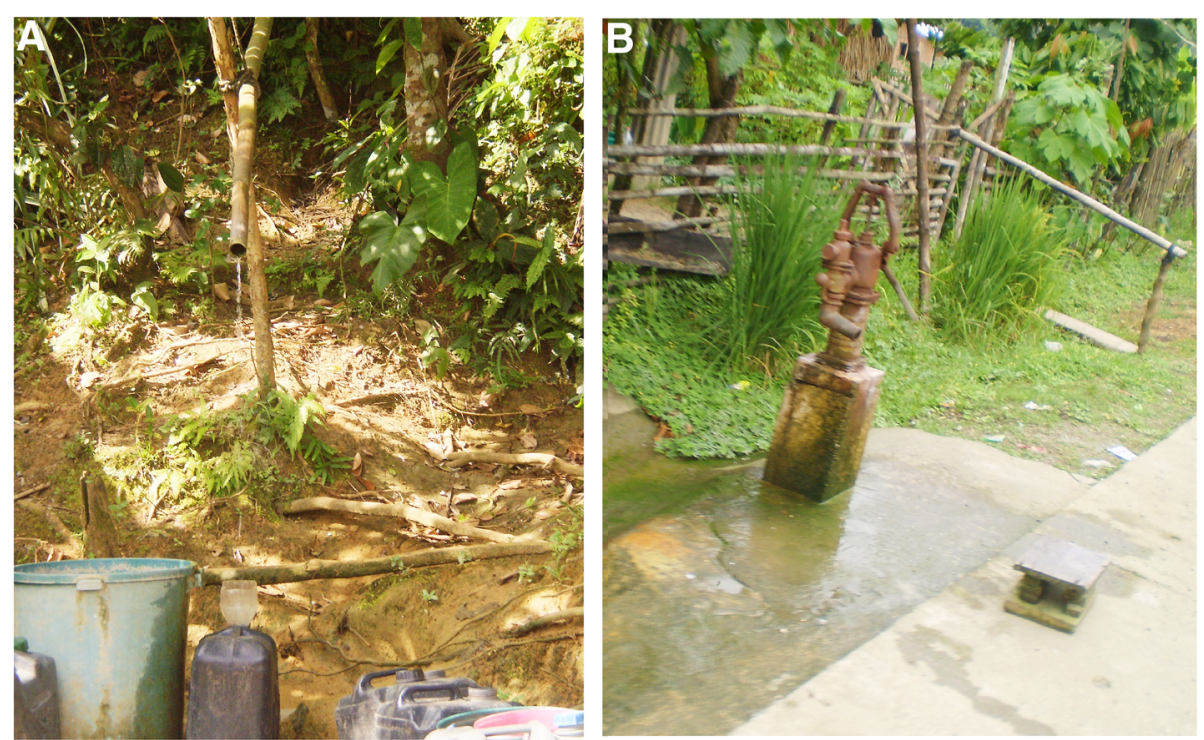

Fig. 4 Some of the sources of water for human consumption in the study region: a Water directed from a spring through an open bamboo tube, b Well pump (depth approximately $5 \mathrm{ft}$ ) 
effects on nutrition, immune status, growth and development, overall physical performance, and also increases the susceptibility to other types of gut pathogens such as cholera and rota virus $[8,28,63-67]$. Clinical manifestations of these chronic complications would mostly be accounted for by social factors such as poor socio-economic status and the protozoan infections may not be clinically suspected, unless the area is well known to be endemic for these infections. Without obvious acute symptoms such as diarrhoea and abdominal pain, and even with these symptoms, protozoan infections can easily be missed with commonly available low sensitivity copro-microscopic diagnostics [30,68] leading to underlying chronic infections persisting with a higher long-term morbidity. It is therefore important to recognize clinical manifestations/patterns of infections of parasite communities, and to consider coinfections rather than just individual infections, all of which will help in early clinical suspicion and appropriate intervention.

It is imperative to use highly sensitive diagnostic tools required to detect asymptomatic infections through community screening so that efficient control and preventive measures can be implemented to target all parasites present in the endemic area. Both microscopic and molecular methods can detect multiple parasites in a single sample. However, copro-microscopic tests have the major drawbacks of being labour intensive, the need of multiple sample testing, the inability to differentiate between closely related species such as hookworms which are morphologically identical, and limited sensitivity particularly in low intensity infections [69, 70]. Hence PCR-based methods such as qPCR and ddPCR, particularly with their multiplexing capability, would be extremely helpful in accurate assessment of both prevalence as well as the intensity of co-parasite infections [30, 71-73].

While the PCR-based molecular assays are highly sensitive in disease diagnosis, they are relatively expensive and hence pose a major challenge for application as a routine diagnostic method and in screening campaigns. Adding to this, the need for advanced and specialized equipment leads to difficulties in establishing novel molecular technology directly in the field, mainly in resource-poor endemic regions. However, as the new technology matures and advances are made, these limitations, costs in particular, are likely to reduce. Despite the current limitations, PCR-based assays could be effectively applied as a monitoring tool for measuring the impact of control strategies by testing random community subsets as well as in secondary surveys for screening microscopy-negative individuals $[5,6,40]$.

\section{Conclusions}

Polyparasitism involving multiple IP infections and $S$. japonicum appears to be highly prevalent in rural Northern Samar province, likely contributing towards significant public health and socio-economic threats in this area and more generally throughout the Philippines. On a broader scale, the identification of individuals with polyparasitism using molecular tools, such as multiplex qPCR, is important as it can provide a measure of disease burden and also is a vital guide for the instigation of specific prevention and control interventions effective against multiple parasites.

\section{Additional file}

Additional file 1: Multilingual abstracts in the five official working languages of the United Nations. (PDF $794 \mathrm{~kb}$ )

\section{Abbreviations \\ Cl: Confidence interval; CNI: Copy number index; ddPCR: Droplet digital PCR; IP: Intestinal protozoa; MDA: Mass drug administration; OR: Odds ratio; PCR: Polymerase chain reaction; QIMR: Queensland Institute of Medical Research; QIMRB: QIMR Berghofer Medical Research Institute; qPCR: Quantitative PCR; STH: Soil transmitted helminths; WASH: Water, sanitation and hygiene}

\section{Acknowledgements}

We acknowledge the support and work by members of the Immunology Laboratory at the Research Institute of Tropical Medicine (RITM), Manila and regional staff from the Palapag and Laoang regions, and also all the study participants. We also acknowledge the help of Professor James McCarthy and Stacey Llewellyn (Clinical Tropical Medicine Group, QIMRB), and Dr. Helle Bielefeldt-Ohmann (School of Veterinary Science, Gatton Campus, The University of Queensland), by providing cultured plasmid DNA of intestinal protozoans. We thank Madeleine Flynn, QIMRB, for her help with preparation of the figures.

\section{Funding}

This work was funded by the National Health and Medical Research Council (NHMRC) of Australia (grant numbers: ID613671, APP1037304, APP1098244). DPM received the grants, and is a NHMRC Senior Principal Research Fellow and Senior Scientist at QIMRB.

\section{Availability of data and materials}

The datasets supporting the conclusions of this article are included within the article.

\section{Authors' contributions}

DPM and KW conceived the idea and designed the study. DPM, AGR, RMO, KW and DUO coordinated sample collection. KW, RMO and DUO carried out the laboratory analysis. KW, GMW, CAG, PC and DPM did data analysis and interpretation. KW drafted the manuscript, and DPM, CAG, GMW, PC, GNG and RAG reviewed and edited the manuscript. All authors read and approved the final manuscript.

\section{Ethics approval and consent to participate}

This study was approved by the QIMRB Human Ethics Committee (Project P288 and Project P524) and the Ethics Committee of the Research Institute for Tropical Medicine (RITM), Manila (Institutional Review Board Number: 2015-12). Informed written consent was obtained from each individual study participant and from the parents/guardians of minors.

\section{Consent for publication}

Not applicable

\section{Competing interests}

The authors declare that they have no competing interests.

\section{Author details}

${ }^{1}$ Molecular Parasitology Laboratory, Infectious Diseases Division, QIMR Berghofer Medical Research Institute, Brisbane 4006, Australia. ${ }^{2}$ School of 
Public Health, The University of Queensland, Brisbane 4006, Australia. ${ }^{3}$ Department of Parasitology, Faculty of Medicine and Allied Sciences, Rajarata University of Sri Lanka, Saliyapura 50008, Sri Lanka. ${ }^{4}$ School of Biological Sciences, Queen's University Belfast, Belfast BT9 7BL, UK. ${ }^{5}$ Research Institute for Tropical Medicine, Department of Health, Manila 1781, Philippines. ${ }^{6}$ Menzies Health Institute Queensland, Griffith University, Gold Coast 4222, Australia.

\section{Received: 7 June 2018 Accepted: 15 November 2018} Published online: 10 December 2018

\section{References}

1. Steinmann P, Utzinger J, Du ZW, Zhou XN. Multiparasitism a neglected reality on global, regional and local scale. Adv Parasitol. 2010;73:21-50.

2. Murray CJL, Vos T, Lozano R, Naghavi M, Flaxman AD, Michaud C, et al. Disability-adjusted life years (DALYs) for 291 diseases and injuries in 21 regions, 1990-2010: a systematic analysis for the global burden of disease study 2010. Lancet. 2012;380:2197-223.

3. Abruzzi A, Fried B. Coinfection of Schistosoma (Trematoda) with bacteria, protozoa and helminths. Adv Parasitol. 2011;77:1-85.

4. Viney ME, Graham AL. Patterns and processes in parasite co-infection. Adv Parasitol. 2013;82:321-69.

5. Gordon CA, McManus DP, Acosta LP, Olveda RM, Williams GM, Ross AG, et al. Multiplex real-time PCR monitoring of intestinal helminths in humans reveals widespread polyparasitism in Northern Samar, the Philippines. Int $J$ Parasitol. 2015;45:477-83.

6. Gordon CA, Acosta LP, Gobert GN, Olveda RM, Ross AG, Williams GM, et al. Real-time PCR demonstrates high prevalence of Schistosoma japonicum in the Philippines: implications for surveillance and control. PLoS Negl Trop Dis. 2015:9:e0003483.

7. Howard SC, Donnell CA, Chan MS. Methods for estimation of associations between multiple species parasite infections. Parasitology. 2001;122:233-51.

8. Supali T, Verweij JJ, Wiria AE, Djuardi Y, Hamid F, Kaisar MMM, et al. Polyparasitism and its impact on the immune system. Int J Parasitol. 2010; 40:1171-6.

9. WHO. Working to overcome the global impact of neglected tropical diseases: first WHO report on neglected tropical diseases. Geneva: World Health Organization; 2010.

10. WHO. The global burden of disease: 2004 update. Geneva: World Health Organization; 2008.

11. Bethony J, Brooker S, Albonico M, Geiger SM, Loukas A, Diemert D, et al. Soil-transmitted helminth infections: ascariasis, trichuriasis, and hookworm. Lancet. 2006;367:1521-32.

12. Stanley SL. Amoebiasis. Lancet. 2003;361:1025-34.

13. Minetti C, Chalmers RM, Beeching NJ, Probert C, Lamden K. Giardiasis BMJ. 2016;355:i5369.

14. Savioli L, Smith H, Thompson A. Giardia and Cryptosporidium join the "neglected diseases initiative". Trends Parasitol. 2006;22:203-8.

15. Feng Y, Xiao L. Zoonotic potential and molecular epidemiology of Giardia species and giardiasis. Clin Microbiol Rev. 2011;24:110-40.

16. Gunawardena K, Kumarendran B, Ebenezer R, Gunasingha MS, Pathmeswaran A, de Silva N. Soil-transmitted helminth infections among plantation sector school children in Sri Lanka: prevalence after ten years of preventive chemotherapy. PLoS Negl Trop Dis. 2011:5:e1341.

17. WHO. Entamoeba taxonomy. Bull World Health Organ. 1997;75:291-4.

18. Escobedo AA, Cimerman S. Giardiasis: a pharmacotherapy review. Expert Opin Pharmacother. 2007:8:1885-902.

19. DuPont HL. Giardia: both a harmless commensal and a devastating pathogen. J Clin Invest. 2013;123:2352-4.

20. Davies AP, Chalmers RM. Cryptosporidiosis BMJ. 2009;339:b4168.

21. Lozano R, Naghavi M, Foreman K, Lim S, Shibuya K, Aboyans V, et al. Global and regional mortality from 235 causes of death for 20 age groups in 1990 and 2010: a systematic analysis for the global burden of disease study 2010. Lancet. 2012;380:2095-128.

22. GBD 2015 Mortality and causes of death collaborators. Global, regional, and national life expectancy, all-cause mortality, and cause-specific mortality for 249 causes of death, 1980-2015: a systematic analysis for the Global Burden of Disease Study 2015. Lancet. 2016;388:1459-544.

23. Stensvold CR, Clark CG. Current status of Blastocystis: a personal view. Parasitol Int. 2016;65:763-71.
24. Stensvold CR, Lewis HC, Hammerum AM, Porsbo LJ, Nielsen SS, Olsen KEP, et al. Blastocystis: unravelling potential risk factors and clinical significance of a common but neglected parasite. Epidemiol Infect. 2009;137:1655-63.

25. Keiser J, N'Goran EK, Traoré $M$, Lohourignon $\mathrm{KL}$, Singer $\mathrm{BH}$, Lengeler $\mathrm{C}$, et al. Polyparasitism with Schistosoma mansoni, geohelminths, and intestinal protozoa in rural Côte d'Ivoire. J Parasitol. 2002;88:461-6.

26. Cox FE. Concomitant infections, parasites and immune responses. Parasitology. 2001;122:S23-38.

27. Keusch GT, Migasena P. Biological implications of polyparasitism. Rev Infect Dis. 1982:4:880-2

28. Al-Shehri H, Stanton MC, LaCourse JE, Atuhaire A, Arinaitwe M, Wamboko A, et al. An extensive burden of giardiasis associated with intestinal schistosomiasis and anaemia in school children on the shoreline of Lake Albert, Uganda. Trans R Soc Trop Med Hyg. 2016;110:597-603.

29. Haque R, Roy S, Siddique A, Mondal U, Rahman SMM, Mondal D, et al. Multiplex real-time PCR assay for detection of Entamoeba histolytica, Giardia intestinalis, and Cryptosporidium spp. Am J Trop Med Hyg. 2007;76:713-7.

30. Llewellyn S, Inpankaew T, Nery SV, Gray DJ, Verweij JJ, Clements ACA, et al. Application of a multiplex quantitative PCR to assess prevalence and intensity of intestinal parasite infections in a controlled clinical trial. PLoS Negl Trop Dis. 2016;10:e0004380

31. Verweij JJ, Stensvold CR. Molecular testing for clinical diagnosis and epidemiological investigations of intestinal parasitic infections. Clin Microbiol Rev. 2014;27:371-418.

32. Olveda DU, Inobaya M, Olveda RM, Vinluan ML, Ng S-K, Weerakoon K, et al. Diagnosing schistosomiasis-induced liver morbidity: implications for global control. Int J Infect Dis. 2017;54:138-44.

33. Ross AGP, Olveda RM, McManus DP, Harn DA, Chy D, Li Y, et al. Risk factors for human helminthiases in rural Philippines. Int J Infect Dis. 2017:54:150-5.

34. Yu W, Ross AG, Olveda RM, Harn DA, Li Y, Chy D, et al. Risk of human helminthiases: geospatial distribution and targeted control. Int J Infect Dis. 2017:55:131-8.

35. Belleza MLB, Cadacio JLC, Borja MP, Solon JAA, Padilla MA, Tongol-Rivera PN, et al. Epidemiologic study of Blastocystis infection in an urban community in the Philippines. J Environ Public Health. 2015;2015:894297.

36. Hotez PJ, Bottazzi ME, Strych U, Chang L-Y, Lim YAL, Goodenow MM, et al. Neglected tropical diseases among the Association of Southeast Asian Nations (ASEAN): overview and update. PLoS Negl Trop Dis. 2015;9:e0003575

37. Baldo ET, Belizario WY, De Leon WU, Kong HH, Chung D-I. Infection status of intestinal parasites in children living in residential institutions in metro Manila, the Philippines. Korean J Parasitol. 2004;42:67-70.

38. Natividad FF, Buerano CC, Lago CB, Mapua CA, de Guzman BB, Seraspe EB, et al. Prevalence rates of Giardia and Cryptosporidium among diarrheic patients in the Philippines. Southeast Asian J Trop Med Public Health. 2008; 39:991-9.

39. Ross AGP, Olveda RM, Chy D, Olveda DU, Li Y, Harn DA, et al. Can mass drug administration lead to the sustainable control of schistosomiasis? J Infect Dis. 2015:211:283-9.

40. Weerakoon KG, Gordon CA, Williams GM, Cai P, Gobert GN, Olveda RM, et al. Droplet digital PCR diagnosis of human schistosomiasis: parasite cell-free DNA detection in diverse clinical samples. J Infect Dis. 2017; 216:1611-22.

41. Stensvold CR, Ahmed UN, Andersen LO, Nielsen HV. Development and evaluation of a genus-specific, probe-based, internal-process-controlled realtime PCR assay for sensitive and specific detection of Blastocystis spp. J Clin Microbiol. 2012;50:1847-51.

42. Tan KSW. New insights on classification, identification, and clinical relevance of Blastocystis spp. Clin Microbiol Rev. 2008;21:639-65.

43. Scanlan PD, Stensvold CR, Rajilić-Stojanović M, Heilig HGHJ, De Vos WM, OToole PW, et al. The microbial eukaryote Blastocystis is a prevalent and diverse member of the healthy human gut microbiota. FEMS Microbiol Ecol. 2014;90:326-30

44. Vogelberg C, Stensvold CR, Monecke S, Ditzen A, Stopsack K, Heinrich-Gräfe $U$, et al. Blastocystis sp. subtype 2 detection during recurrence of gastrointestinal and urticarial symptoms. Parasitol Int. 2010;59:469-71.

45. Poirier $P$, Wawrzyniak I, Vivarès $C P$, Delbac F, El Alaoui H. New insights into Blastocystis spp.: a potential link with irritable bowel syndrome. PLoS Pathog. 2012;8:e1002545.

46. Fink MY, Singer SM. The intersection of immune responses, microbiota, and pathogenesis in giardiasis. Trends Parasitol. 2017;33:901-13. 
47. Turkeltaub JA, McCarty TR, Hotez PJ. The intestinal protozoa: emerging impact on global health and development. Curr Opin Gastroenterol. 2015; 31:38-44.

48. Troeger C, Forouzanfar M, Rao PC, Khalil I, Brown A, Reiner RC, et al. Estimates of global, regional, and national morbidity, mortality, and aetiologies of diarrhoeal diseases: a systematic analysis for the global burden of disease study 2015. Lancet Infect Dis. 2017;17:909-48.

49. Tandon BN, Tandon RK, Satpathy BK. Shriniwas. Mechanism of malabsorption in giardiasis: a study of bacterial flora and bile salt deconjugation in upper jejunum. Gut. 1977;18:176-81.

50. Blackwell AD, Martin M, Kaplan H, Gurven M. Antagonism between two intestinal parasites in humans: the importance of co-infection for infection risk and recovery dynamics. Proceedings Biol Sci. 2013;280:20131671.

51. Sevilimedu V, Pressley KD, Snook KR, Hogges JV, Politis MD, Sexton JK, et al. Gender-based differences in water, sanitation and hygiene-related diarrheal disease and helminthic infections: a systematic review and meta-analysis. Trans R Soc Trop Med Hyg. 2017;110:637-48.

52. Vlassoff C. Gender differences in determinants and consequences of health and illness. J Health Popul Nutr. 2007;25:47-61.

53. Roberts CW, Walker W, Alexander J. Sex-associated hormones and immunity to protozoan parasites. Clin Microbiol Rev. 2001;14:476-88.

54. Steketee RW. Pregnancy, nutrition and parasitic diseases. J Nutr. 2003;133: 1661S-7S.

55. Koruk I, Simsek Z, Tekin Koruk S, Doni N, Gürses G. Intestinal parasites, nutritional status and physchomotor development delay in migratory farm worker's children. Child Care Health Dev. 2010;36:888-94

56. Halliez MCM, Buret AG. Extra-intestinal and long term consequences of Giardia duodenalis infections. World J Gastroenterol. 2013;19:8974-85.

57. Campbell SJ, Savage GB, Gray DJ, Atkinson J-AM, Soares Magalhães RJ, Nery SV, et al. Water, sanitation, and hygiene (WASH): a critical component for sustainable soil-transmitted helminth and schistosomiasis control. PLoS Negl Trop Dis. 2014;8:e2651.

58. Speich B, Croll D, Fürst T, Utzinger J, Keiser J. Effect of sanitation and water treatment on intestinal protozoa infection: a systematic review and metaanalysis. Lancet Infect Dis. 2016;16:87-99.

59. Harhay MO, Horton J, Olliaro PL. Epidemiology and control of human gastrointestinal parasites in children. Expert Rev Anti-Infect Ther. 2010;8: 219-34.

60. McSorley HJ, Maizels RM. Helminth infections and host immune regulation. Clin Microbiol Rev. 2012:25:585-608.

61. Borkow G, Bentwich Z. Chronic parasite infections cause immune changes that could affect successful vaccination. Trends Parasitol. 2008:24:243-5.

62. Bustinduy AL, Sousa-Figueiredo JC, Adriko M, Betson M, Fenwick A, Kabatereine $\mathrm{N}$, et al. Fecal occult blood and fecal calprotectin as point-ofcare markers of intestinal morbidity in Ugandan children with Schistosoma mansoni infection. PLoS Negl Trop Dis. 2013;7:e2542.

63. Pullan R, Brooker S. The health impact of polyparasitism in humans: are we under-estimating the burden of parasitic diseases? Parasitology. 2008;135: 783-94.

64. Mupfasoni D, Karibushi B, Koukounari A, Ruberanziza E, Kaberuka T, Kramer $\mathrm{MH}$, et al. Polyparasite helminth infections and their association to anaemia and undernutrition in northern Rwanda. PLoS Negl Trop Dis. 2009;3:e517.

65. Ezeamama AE, Friedman JF, Olveda RM, Acosta LP, Kurtis JD, Mor V, et al. Functional significance of low-intensity polyparasite helminth infections in anemia. J Infect Dis. 2005;192:2160-70.

66. Sokhna C, Le Hesran J-Y, Mbaye PA, Akiana J, Camara P, Diop M, et al. Increase of malaria attacks among children presenting concomitant infection by Schistosoma mansoni in Senegal. Malar J. 2004;3:43.

67. Ross AGP, Olds GR, Cripps AW, Farrar JJ, McManus DP. Enteropathogens and chronic illness in returning travelers. N Engl J Med. 2013;368:1817-25.

68. McHardy $\mathrm{H}$, Wu M, Shimizu-Cohen R, Couturier MR, Humphries RM. Detection of intestinal protozoa in the clinical laboratory. J Clin Microbiol. 2014;52:712-20.

69. Cringoli G, Rinaldi L, Maurelli MP, Utzinger J. FLOTAC: new multivalent techniques for qualitative and quantitative copromicroscopic diagnosis of parasites in animals and humans. Nat Protoc. 2010;5:503-15.

70. Barda B, Cajal P, Villagran E, Cimino R, Juarez M, Krolewiecki A, et al. MiniFLOTAC, Kato-Katz and McMaster: three methods, one goal; highlights from North Argentina. Parasit Vectors. 2014;7:271
71. Verweij JJ, van Lieshout L. Intestinal parasitic infections in an industrialized country; a new focus on children with better DNA-based diagnostics. Parasitology. 2011;138:1492-8.

72. Knopp S, Salim N, Schindler T, Karagiannis Voules DA, Rothen J, Lweno O, et al. Diagnostic accuracy of Kato-Katz, FLOTAC, Baermann, and PCR methods for the detection of light-intensity hookworm and Strongyloides stercoralis infections in Tanzania. Am J Trop Med Hyg. 2014;90:535-45.

73. Mejia R, Vicuña Y, Broncano N, Sandoval C, Vaca M, Chico M, et al. A novel, multi-parallel, real-time polymerase chain reaction approach for eight gastrointestinal parasites provides improved diagnostic capabilities to resource-limited at-risk populations. Am J Trop Med Hyg. 2013;88:1041-7.

\section{Ready to submit your research? Choose BMC and benefit from:}

- fast, convenient online submission

- thorough peer review by experienced researchers in your field

- rapid publication on acceptance

- support for research data, including large and complex data types

- gold Open Access which fosters wider collaboration and increased citations

- maximum visibility for your research: over $100 \mathrm{M}$ website views per year

At $\mathrm{BMC}$, research is always in progress.

Learn more biomedcentral.com/submissions 